\title{
VII. On the relation between viscosity and atomic weight for the inert gases; with its application to the case of radium emanation
}

\section{A.O. Rankine D.Sc.}

To cite this article: A.O. Rankine D.Sc. (1911) VII. On the relation between viscosity and atomic weight for the inert gases; with its application to the case of radium emanation, Philosophical Magazine Series 6, 21:121, 45-53, DOI: 10.1080/14786440108637004

To link to this article: http://dx.doi.org/10.1080/14786440108637004

冓 Published online: 21 Apr 2009.

Submit your article to this journal

Џll Article views: 5

Q View related articles $\longleftarrow$

Citing articles: 3 View citing articles ᄃ 
to repeat the observations with different values of $\mathrm{V}_{1}$ and $\mathrm{V}_{2}$, and, consequently, different values of $v$. The method may also be applied to the determination of the capacity of condensers designed to serve as secondary standards. These condensers can be used as "auxiliary" condensers, and the determination of their capacities will have the same accuracy whatever the ratio of those capacities to that of the measuring system.

It is found in practice that it is quite easy to attain such aceuracy that the probable error of the value deduced from a single observation is not greater than 1 per cent.

Leeds, September 1910.

VII. On the Relation between Viscosity and Atomic Weight for the Inert Gases; with its Application to the case of Radium Emanation. By A. O. RANKIne, D.Se., Assistant in the Department of Physics, University of London, University College*

A FURTHER examination of the data obtained in my A measurements of the viscosities of the gases of the argon group $\dagger$ has brought to light a simple relation between viscosity and atomic weight. This relation has some important applications. It may be used, as will be shown, to form an estimate of the critical temperature of neon. Further, in conjunction with another relation previously published, it renders possible the estimation of the viscosity and molecular dimensions of radium emanation, upon the assumption that this gas belongs to the argon group.

The data upon which the present paper is based are given in Table I.

TABLE I.

\begin{tabular}{|c|c|c|}
\hline Gas. & $\eta_{0} \times 10^{4}$. & c. \\
\hline He & 1.879 & 70 \\
\hline $\mathrm{Ne}$ & $2 \cdot 981$ & 56 \\
\hline …...... & $2 \cdot 102$ & 142 \\
\hline $\mathrm{Kr} \quad \ldots \ldots . .$. & $2 \cdot 334$ & 188 \\
\hline $\mathbf{x}$ & $2 \cdot 107$ & 252 \\
\hline
\end{tabular}

- Ccmmunicäted by Prof. F. T. Trouton, F.R.S.

† Proc. Roy. Soc. A, vol. Txaxiii. p. 516, and Proc. Roy. Soc. A, vol. 1xxxiv, p. 181 . 
The numbers in the second column are the viscosities in absolute units at $0^{\circ} \mathrm{C}$. multiplied by $10^{4}$. Those in the third column are the values of the constant $C$ in Sutherland's * equation

$$
\eta=\eta_{0}\left(\frac{\mathrm{T}}{\mathrm{T}_{0}}\right)^{\frac{3}{3}}\left(\frac{\mathrm{C}+\mathrm{T}_{0}}{\mathrm{C}+\mathrm{T}}\right),
$$

where $\eta$ is the viscosity at the absolute temperature $\mathrm{T}$.

The first five points in fig. 1 show the viscosities at

Fig. 1.

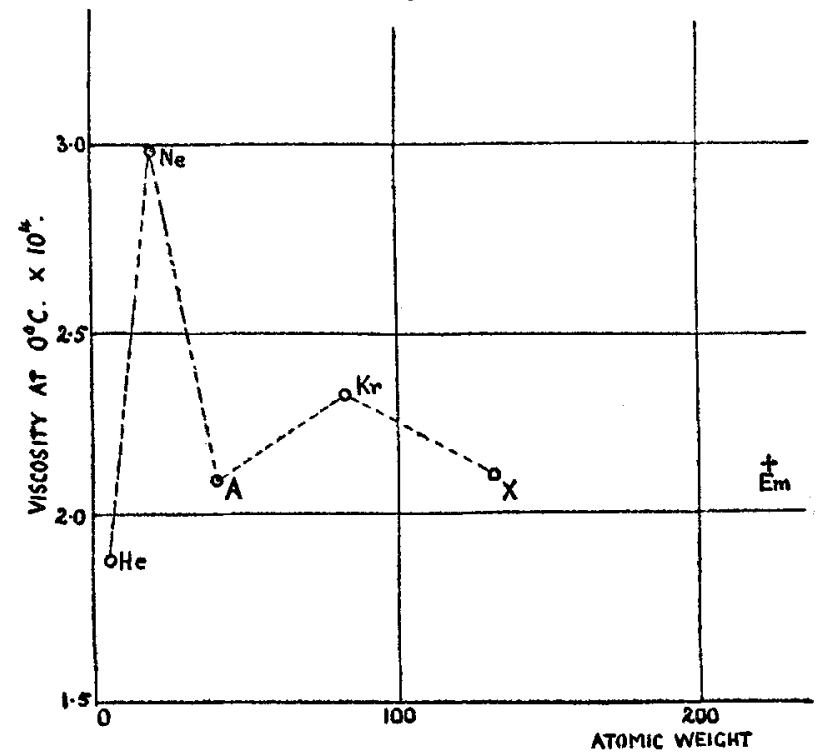

$0^{\circ} \mathrm{C} . \times 10^{4}$ plotted against the atomic weight. The undulatory nature of the curve is apparent, and it is at once recognized that no simple algebraic relationship obtains. Indeed, such a connexion is hardly to be expected in view of the fact that comparison is made of the viscosities of the gases at the same temperature. It seems much more reasonable to perform the comparison at corresponding temperatures-for example, the boiling points or critical temperatures of the respective gases. With the data available this procedure is only possible if the truth of Sutherland's equation be assumed, and the values of the viscosity found by extrapolation. In this manner the viscosities of the gases have been calculated, with the striking

* Plil. Mag. 1893, vol. xxxri. p. 507. 
Viscosity and Atomic Weight for the Inert Gases.

result that the viscosity-atomic weight curve becomes smooth, and the square of the viscosity at the critical point is found to be proportional to the atomic weight. This relation has been deduced from the values for argon, krypton, and xenon only, because the critical temperature of neon has not been determined, and that of belium is not known with certainty.

The curve in fig. 2 is the parabola whose equation is

$$
\frac{\eta_{c}^{2}}{\mathrm{~A}}=3.93 \times 10^{-10},
$$

Fig. 2.

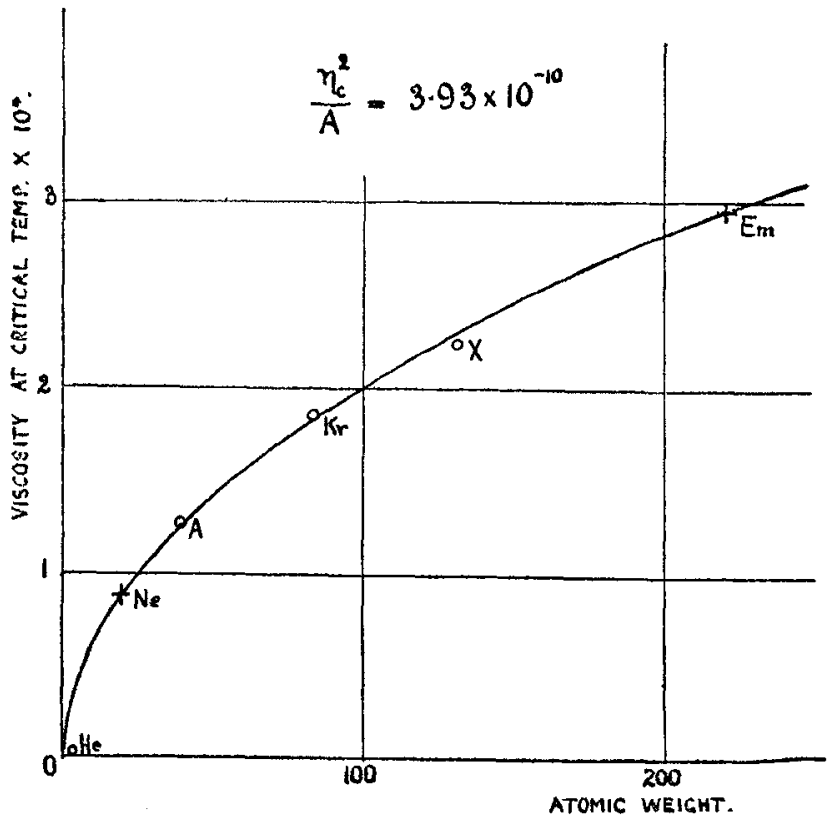

where $\eta_{c}$ is the viscosity at the critical temperature and A is the atomic weigbt. The calculated value of $\eta_{c}$ for belium (assuming the probable value $5^{\circ}$ absolute for the critical temperature) is also shown on the curve. It will be seen that it is considerably removed from the theoretic curve, and it should be pointed out that the uncertainty as to the critical temperature is whoily insufficient to account for the departure. 
Table II. shows the numbers relating to the curve.

TABLE II.

\begin{tabular}{|c|c|c|c|c|c|}
\hline Gas. & $\mathrm{T}_{c}$ & A. & $\eta_{c} \times 10^{4}$ & $\begin{array}{c}\eta_{c} \times 10^{4} \\
\text { (calculated) }\end{array}$ & $\begin{array}{l}\text { Difference } \\
\text { per cent. }\end{array}$ \\
\hline He ........ & (5)? & $3 \cdot 96$ & 0.021 & 0.32 & $\ldots$ \\
\hline $\mathrm{Ne} . . . . .$. & $\ldots$ & $20 \cdot 03$ & $\ldots$ & $\ldots$ & $\ldots$ \\
\hline A .. & $155 \cdot 6$ & $39 \cdot 92$ & $1 \cdot 261$ & $1 \cdot 253$ & 06 \\
\hline Kr ..... & 210.5 & $83 \cdot 0$ & $1 \cdot 8 \geq 8$ & 1.806 & 1.2 \\
\hline $\mathbf{x} .$. & 288 & $130 \cdot 7$ & $2 \cdot 220$ & $2 \cdot 266$ & $-2 \cdot 1$ \\
\hline
\end{tabular}

The numbers in the fourth column are calculated from Sutherland's equation nsing $\eta_{0}, \mathrm{C}$, and $\mathrm{T}_{c}$; those in the fifth column are deduced from the equation

$$
\frac{\eta_{c}^{2}}{\mathrm{~A}}=3.93 \times 10^{-10} \text {. }
$$

With the exception of helium this equation is a good fit, and even the exception seems capable of reasonable explanation. In the cases of helium and argon we may avoid the necessitv of such extensive extrapolation by using the experiment:1 results recorded by Schmitt*. These measurements extend from $-193^{\circ} \cdot 2 \mathrm{C}$. to $+183^{\circ} .7 \mathrm{C}$., and the value of the viscosity of argon at the critical temperature can be deduced by interpolation. The value thus obtained is $1.25 \times 10^{-4}$, which is remarkably near the value calculated here, and suggests that in this case the extrapolation is valid. When we turn to helium, however, the results are very different. At a temperature of $80^{\circ}$ absolute the actual value of the viscosity exceeds that calculated by using Sutherland's equation by 26 per cent., and the divergence increases with fall of temperature. The temperature at which the riscosity is required is $5^{\circ}$ absolute, or $75^{\circ}$ lower, where we should expect the divergence to be more serious still. In fact, an extrapolation over this range of 75 degrees indicates that $0.32 \times 10^{-4}$ is a much moie probable value of the actual viscosity at $5^{\circ} \mathrm{C}$. than $0.021 \times 10^{-4}$. This would bring helium into line with the other gases. It is quite possible, therefore, that helium also conforms with the law here presented, and that the apparent divergence should be attributed to the failure of Sutherland's equation at temperatures so near to absolute zero.

\footnotetext{
* Ann, der Physik, Bd. xxx. Heft 2, p. 399 (1909).
} 


\section{Viscosity and Atomic Weight for the Inert Gases. \\ The Critical Temperature of Neon.}

It is evident that, working backwards, this relation may be used to estimate the critical temperature of neon, upon the assumption thit it applies for this gas. In that case the value of $\eta_{c}$ for neon (shown by a cross in the diagram) would be $0.887 \times 10^{-4}$. This, according to Sutherland's equation, would be the viscosity of neon at a temperature of $61^{\circ} \cdot 1$ absolute. That is to say, the critical temperature of neon is $61^{\circ} \cdot 1$ absolute.

The author * has already made an estimate of this temperature based upon another relation, namely, that the critical temperature is proportional to Sutherland's constant. This is expressed by the equation

$$
\mathrm{T}_{c}=1 \cdot 12 \mathrm{C} .
$$

Taking the value $C=56$ obtained from the experiments, this gives $T_{c}=62^{\circ} \cdot 7$ absolute. The agreement between these two figures 61.1 and 62.7 is remarkable, and constitutes weighty evidence of the probable accuracy of the estimate.

\section{Application to Radium Emanation.}

It is generally accepted that the emanation from radium belongs to the same group in the periodic table as the gases previously referred to. There is considerable justification, therefore, for applying the two above-mentioned relations to this case. The fact that the atomic weight and critical temperature of the emanation are now known renders it possible to estimate the viscosity, not only at the critical point, but also at any other temperature, together with the dependent molecular properties.

The values of the atomic weight and critical temperature used are those obtained by Ramsay and Gray $\dagger$, viz. $A=222$ and $\mathrm{T}_{c}=377^{\circ}$ absolute.

In the first place, using the relation

we obtain $\mathrm{C}=337$.

$$
\mathrm{T}_{c}=1 \cdot 12 \mathrm{C} \text {, }
$$

Further, using the second relation

$$
\eta_{c}^{2}=\frac{3 \cdot 93}{10^{10}} \cdot \mathrm{A}
$$

$\eta_{c}$ is found to be $2.954 \times 10^{-4}$. [This is shown by the cross marked $E m$ on figure 2:]

* Proc. Roy. Soc. A, rol. lxxxiv. p. 190.

† Trans. Chem. Soc. 1909, p. 1073. Brit. Assoc. Report, Sheftield, 1910.

Plit. Mag. S. 6. Vol. 21. No. 122. Jan. 1911. 
Now, making use of Sutherland's equation

$$
\eta_{0}=\eta_{c}\left(\begin{array}{l}
\mathrm{T}_{0} \\
\overline{\mathrm{T}}_{c}
\end{array}\right)^{\frac{3}{2}}\left(\frac{\mathrm{C}+\mathrm{T}_{c}}{\mathrm{C}+\mathrm{T}_{0}}\right)
$$

as applied to the emanation we obtain

$$
\begin{aligned}
\eta_{0} & =2 \cdot 954\left(\frac{273}{377}\right)^{\frac{3}{2}}\left(\frac{714}{610}\right) \cdot 10^{-4} \\
& =2 \cdot 130 \times 10^{-4}
\end{aligned}
$$

This is the estimated value of the viscosity of radium emanation at $0^{\circ} \mathrm{C}$. It is recorded by means of the cross on fig. 1. It lies between the values for xenon and krypton, and its position strongly suggests that the up and down distribution of the points is not without significance. The alternations were already regular but of decreasing amplitude before the addition of the point representing the emanation; its addition carries the rule a step further in both respects. Of course, it is possible that another unidentified member of this group of gases lies between xenon and radium emanation; but it will be seen that a place conld be found for it on the diagram. Indeed, a point higher than $\mathrm{X}$ or $\mathrm{Em}$ and lower than $\mathrm{Kr}$, placed abont midway between $\mathrm{X}$ and Em, would be more in keeping with the general trend of distribution than a single step from $\mathrm{X}$ to $\mathrm{Em}$.

It is now possible to compare the molecular dimensions of emanation and helium, since the viscosities at the same temperature are known. The connexion according to the kinetic theory is

$$
\frac{s_{\mathrm{Em}}^{2}}{s_{\mathrm{He}}^{2}}=\frac{\eta_{\mathrm{He}}}{\eta_{\mathrm{Em}}} \sqrt{\frac{\rho_{\mathrm{Em}}}{\rho_{\mathrm{He}}}},
$$

where $s$ is the radius of the molecule and $\rho$ the density of the gas under constant conditions. This gives

and consequently

$$
\frac{s_{\mathrm{Em}}}{s_{\mathrm{He}}}=2 \cdot 57
$$

$$
\frac{v_{\mathrm{Em}}}{v_{\mathrm{He}}}=16 \cdot 97
$$

where $v$ denotes the molecular volume.

Thus the molecule of emanation is larger than that of any other known gas in the group, as will be seen from the following table. The other figures are copied from a 
previous paper for purposes of comparison, helium in all cases being taken as unity.

The last three columns refer to the molecular dimensions corrected according to Sutherland's theory. This is that owing to the increased frequency of collision caused by molecular attractions, the molecules behave as though their dimensions were greater than their rell values. If we wish to find the true radius we must diminish that calculated by the simple theory in the proportion $1:\left(1+\frac{\mathrm{C}}{\mathrm{T}}\right)^{\frac{1}{}}$. The numbers in the last three columns are obtained from columns 3 to 5 by the application of this process.

TABLE III.

\begin{tabular}{|c|c|c|c|c|c|c|c|}
\hline \multirow[b]{2}{*}{ Gas. } & \multirow[b]{2}{*}{$\begin{array}{c}\text { Relative } \\
\text { Atomic wt. }\end{array}$} & \multirow[b]{2}{*}{$\begin{array}{c}\text { Molecular } \\
\text { Radius. }\end{array}$} & \multirow[b]{2}{*}{$\begin{array}{c}\text { Molecular } \\
\text { Volume. }\end{array}$} & \multirow[b]{2}{*}{$\begin{array}{c}\text { Density } \\
\text { of the atom. }\end{array}$} & \multicolumn{3}{|c|}{ With Sutherland correction. } \\
\hline & & & & & $\begin{array}{c}\text { Molecular } \\
\text { Radius. }\end{array}$ & $\begin{array}{c}\text { Molecular } \\
\text { Volume. }\end{array}$ & $\begin{array}{c}\text { Density } \\
\text { of the atom. }\end{array}$ \\
\hline He ... & $1 \cdot 00$ & $1 \cdot 00$ & $1 \cdot 00$ & $1 \cdot 00$ & 1.00 & 1.00 & 1.00 \\
\hline No ... & 5.06 & $1 \cdot 19$ & $1 \cdot 69$ & $2 \cdot 99$ & $1 \cdot 21$ & $1 \cdot 79$ & $2 \cdot 83$ \\
\hline A $\quad \ldots$ & $10 \cdot 08$ & $1 \cdot 68$ & 474 & $2 \cdot 12$ & 1.53 & 3.59 & 281 \\
\hline $\mathbf{K} \mathbf{r} \ldots$ & 2096 & $1 \cdot 91$ & 6.08 & 300 & $1 \cdot 65$ & 4.53 & 463 \\
\hline $\mathbf{x} \quad \ldots$ & 3301 & $2 \cdot 25$ & $11 \cdot 37$ & $2 \cdot 90$ & 1.83 & $6 \cdot 11$ & $5 \cdot 40$ \\
\hline $\operatorname{Em} . .$. & 555 & $2 * 57$ & 16.97 & $3 \cdot 28$ & $1 \cdot 93$ & $7 \cdot 16$ & $7 \cdot 75$ \\
\hline
\end{tabular}

Finally, using the value $\mathrm{N}=2.8 \times 10^{19}$ for the number of atoms per c.c. at N.T.P., we obtain for the absolute molecular radius of radium emanation

$$
s_{\mathrm{Em}}=2 \cdot 16 \times 10^{-8} \mathrm{~cm} \text {. }
$$

This is the uncorrected value, i.e. the value obtained without applying the Sutherland diminution, it being still customary to record molecular dimensions in this way.

In order to avoid confusion with regard to these two separate measures of the molecular radius, the following consideration may be found useful.

Rayleigh* has pointed out that if the molecules mutually attract one another, mutual repulsions must also exist, and that the laws of variation of force with distance are different

* Phil. Mrg. Xxx. pp. 285 \& 456 (1890). 
52 Relution between Viscosity and Atomic Weight for Gases.

in the two cases, the variation being necessarily more rapid for the repulsive force. Perhaps from this point of view we should regard the uncorrected radius as referring more particularly to distances from the centre of the atom at which the values of the attractive force become serious, and the corrected or Sutherland radius as the distance at which the forces of repulsion and attraction balance one another.

\section{Connexion between the Critical Temperature and Molecular Radius.}

It will now be shown that a simple relation exists between the critical temperatures of these gases and their molecular dimensions. Starting from the equation

$$
\eta=\frac{1}{3} n m \mathrm{~V} \lambda
$$

obtained from the kinetic theory; $\eta$ being the viscosity, $n$ the number of molecules per c.c., $m$ the molecular mass, $V$ the root maan square velocity, and $\lambda$ the effective mean free path. Hence

$$
\eta^{2}=\frac{1}{9} n^{2} m^{2} V^{2} \lambda^{2}
$$

Now, $m \mathrm{~V}^{2}$ is proportional to $\mathrm{T}$, the absolute temperature. Therefore

$$
\frac{\eta^{2}}{m}=\mathrm{K} \cdot n^{2} \mathrm{~T} \lambda, \text {. . . . . . . }
$$

where $K$ is a constant not depending on the particular gas. Further,

$$
\lambda=\frac{1}{\sqrt{2} n \pi s^{2}}
$$

where $s$ is the effective radius. According to Sutherlanl,

$$
s^{2}=s_{0}^{2}\left(1+\frac{\mathrm{C}}{\mathrm{T}}\right)
$$

where $s_{0}$ is the real radius. Whence

Combining with (1) we obtain

$$
\lambda^{2}=\frac{1}{2 \pi^{2} n^{2} s_{0}^{4}\left(1+\frac{\left(\frac{G}{T}\right)^{2}}{2}\right.} \cdot . .
$$

$$
\frac{\eta^{2}}{m}=q \frac{\mathrm{T}}{s_{0}^{4}\left(1+\frac{\mathrm{C}}{\mathrm{T}}\right)^{2}} \text {. . . . . . }
$$

$q$ being a constant. Now the author has shown that at the 
Vibrations of a Circular Membrane. critical temperature $\frac{\eta^{2}}{m}$ and $1+\frac{\mathrm{C}}{\mathrm{T}}$ are constant. Therefore,
from (3)

$$
\frac{T_{c}}{s_{0}^{4}}=\text { constant. }
$$

That is, the critical temperature, and therefore $\mathrm{C}$ also, is proportional to the fourth power of the true atomic radius. The truth of this law depends on the accuracy of the two laws previously given, and the figures given in column 4 of Table IV. are expected to be constant. The numbers in column 2 are relative to helium.

\section{TABLE IV.}

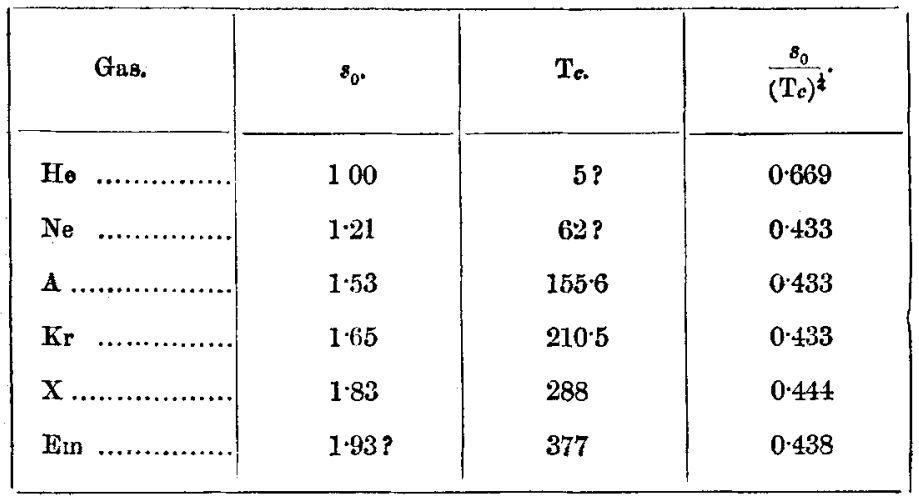

The values to which doubt attaches or which are deduced from previous considerations in this paper are marked with a query. Helium, as one would expect, is an exception. This and the constancy of the remaining ratios are direct consequences of the relations previously given.

VIII. Note on Bessel's Functions as applied to the Vibrations of a Circular Membrane. By Lord RAyLeigh, O.M., F.R.S.*

$T T$ often happens that physical considerations point to 1 analytical conclusions not yet formulated. The pure mathematician will admit that arguments of this kind are suggestive, while the physicist may regard them as conclusive.

The first question here to be touched upon relates to the dependence of the roots of the function $J_{n}(z)$ upon the order

* Communicated by the Author. 